\title{
ANÁLISES FíSICO-QUÍMICAS DE LEITE EM UM LATICÍNIO SOB SERVIÇO DE INSPEÇÃO FEDERAL
}

\author{
Lidiana de Paula Silva* \\ Juliana Ribeiro Lucci ${ }^{\text {** }}$ \\ Anna Marcella Neves Dias ${ }^{* * *}$ \\ Emilia Maricato Pedro Santos
}

\begin{abstract}
RESUM0: 0 leite é um dos alimentos mais nutritivo e consumido em todo mundo e sua qualidade está correlacionada ao equilíbrio dos elementos que 0 compõem e alterações nestes levam a modificações nos fatores físico-químicos e microbiológicos do produto, estando associados à higiene, ao manejo, à alimentação, ao uso de medicamentos, ao armazenamento e ao transporte da matéria-prima até a indústria. A composição do leite é de extrema importância para a indústria de laticínios, visto que está diretamente relacionada ao seu rendimento industrial. 0 objetivo deste trabalho foi realizar análises físico-químicas em um laticínio no período de três meses, a fim de verificar a existência de não conformidades no leite cru recebido por esse estabelecimento. Os seguintes testes foram realizados: álcool-alizarol, pH, acidez titulável, determinação do índice crioscópico, densidade, extrato seco total, extrato seco desengordurado, proteína, lactose, gordura e, ainda, pesquisa de antimicrobianos, reconstituintes de densidade, conservantes e neutralizantes de acidez. Os resultados demonstraram que mesmo com algumas variações nos constituintes do leite, a média da matéria-prima recebida pela indústria enquadra-se nos índices exigidos pela legislação vigente, podendo-se concluir que o leite produzido na região é de boa qualidade.
\end{abstract}

PALAVRAS-CHAVES: Composição centesimal; Lácteos; Qualidade.

\section{PHYSICAL AND CHEMICAL ANALYSIS OF MILK IN A DAIRY UNDER FEDERAL INSPECTION}

\begin{abstract}
Milk is one of the most nutritive and consumed food and its quality is correlated to a balance of factors in its composition. Their changes cause modifications in physical and microbiological factors of the product, associated with hygiene, management, food, use of medicines, storage and transport of the prime matter to the industry. Milk composition is highly relevant for dairies since it is related to industrial yield. Physical and chemical analyses were undertaken in a dairy during three months to verify whether there were any non-conformity items in raw milk received. The following tests were undertaken: alcohol-alizarol; $\mathrm{pH}$, titer acidity, determination of cryoscopic index, density, total dry extract, dry defatted extract, protein, lactose, fat, antimicrobial research, density reconstitution, conservers and acidity neutralizers. Results show that, even with small variations in milk constituting factors, the prime matter received by the dairy lies within indexes required by current legislation, proving the good quality of milk produced in the region.
\end{abstract}

KEYWORDS: Chemical composition; Milk products; Quality.

\section{INTRODUÇÃo}

0 leite, sem outras especificações, é o produto oriundo da ordenha completa e interrupta, em condições de higiene, de vacas sadias, bem alimentadas e descansadas (BRASIL, 2017). 0 leite de outros animais deve denominar-se segundo a espécie que se proceda, de acordo com o Regulamento da Inspeção Industrial e

\footnotetext{
" Graduanda em Medicina veterinária pelo Centro Universitário Presidente Antônio Carlos - UNIPAC, Juiz de Fora (MG), Brasil.

* Centro Universitário Presidente Antônio Carlos - UNIPAC, Juiz de Fora (MG), Brasil.

${ }^{* * *}$ Centro Universitário Presidente Antônio Carlos - UNIPAC, Juiz de Fora (MG), Brasil.

${ }_{*}^{* * * x}$ Médica Veterinária, Doutora em Ciência Animal - Universidade Federal de Juiz de Fora, Juiz de Fora (MG), Brasil.

E-mail: emilia.maricato@ufjf.edu.br
} 
Sanitária dos Produtos de Origem Animal (RIISPOA) vigente no Brasil desde 2017 (BRASIL, 2017).

0 leite é um dos produtos mais consumidos no mundo, sendo de extrema importância na alimentação humana principalmente durante a infância e na senilidade. É considerado o alimento mais completo disponível, tendo como principal componente a água, além de vitaminas, minerais, proteínas, gorduras e carboidratos que compõem a parte sólida do mesmo (ELIAS et al., 2014).

De forma mais específica, dentro dos elementos sólidos do leite (12 a 14\%), os lipídeos representam $3,5 \%$ a $4,5 \%$, os carboidratos $4,6 \%$ a $5,2 \%$, proteínas $3,2 \%$ a $3,5 \%$ e as vitaminas e minerais cerca de $1 \%$. As proteínas presentes nesse alimento são de alto valor biológico, sendo compostas por diversos aminoácidos essenciais. A cianocobalamina, vitamina presente exclusivamente em alimentos de origem animal, também está presente na composição do leite (SOARES, 2013).

A produção leiteira ocupa um espaço de destaque na economia mundial (OECD-FA0, 2019), sendo um dos sistemas industriais mais expressivos no Brasil (EMBRAPA, 2016), onde o leite é consumido de forma in natura ou por meio de seus derivados, sendo uma importante fonte nutricional ao ser humano (VENTUROSO et al., 2007). No Brasil, o mercado de derivados lácteos é importante, porém, o maior consumo de leite ocorre na forma de leites fluidos (ZACARCHENCO et al., 2017).

Vinte grandes indústrias de laticínios concentram $25,4 \%$ de toda a produção de lácteos do mercado mundial (TERRA VIVA, 2016). Em relação ao Brasil, em 2016, 15 empresas foram responsáveis pela captação de um total de 9,67 bilhões de litros de leite, cerca de $27,0 \%$ da produção total inspecionada de leite no mesmo ano (35,66 bilhões) (PILA, 2017). Entretanto, pequenas e médias empresas desempenham papel importante na Cadeia Produtiva de Lácteos no país (ASSIS et al., 2016; BRUNOZI JÚNIOR et al., 2012).

Como dito anteriormente, o leite é um alimento completo em questões nutritivas, e devido a isso 0 mesmo, consequentemente, apresenta características favoráveis para crescimento de micro-organismos, como as leveduras, fungos e principalmente as bactérias, os quais são responsáveis por diminuírem a qualidade microbiológica e vida útil do produto, além de promover um risco à saúde pública (PINT0 et al., 2012). Dessa forma, a qualidade do produto está relacionada com 0 equilíbrio dos elementos que o compõem e as alterações destes levam a modificações nos fatores físico-químicos e microbiológicos do produto, estando associados à higiene, ao manejo, à alimentação, ao uso de medicamentos, ao armazenamento e ao transporte da matéria-prima até a indústria (FERNANDES; MARICATO, 2010).

A qualidade do leite pode ser determinada por meio de avaliações físicas, químicas, microbiológicas e sensoriais. A análise físico-química do leite cru e pasteurizado, bem como análises que detectam adulterações no produto, devem ser realizadas em laticínios com base nos padrões mínimos exigidos pelo Ministério da Agricultura, Pecuária e Abastecimento (MAPA) conforme a legislação vigente, a Instrução Normativa 76/2018 (BRASIL, 2018a).

Nesse contexto, ao analisarem amostras de leite cru clandestino na cidade de Juiz de Fora, MG, Protta et al. (2017) observaram que 63\% das amostras apresentaram resultado de acidez fora da normalidade. Além disso, os autores verificaram que todas as amostras que apresentaram acidez elevada também apresentaram contagens de micro-organismos mesófilos aeróbios acima do padrão previsto pela legislação. Este resultado de acidez corrobora a alta contaminação microbiana.

Pesquisa científicas também demonstram que a fraude do leite ainda é prática comum no Brasil (MENDES et al., 2010; CORRÊA et al., 2015), sendo as mais comuns a adição de água, o desnate e a adição de reconstituintes da densidade, neutralizantes da acidez e substâncias conservantes (TRONCO, 2013; KARTHEEK et al., 2011). Adulterações são decorrências de tentativa de aumentar a lucratividade e causam prejuízo ao consumidor tanto do ponto de vista econômico quanto de segurança do alimento, já que a adição de substâncias químicas ao leite pode causar 
danos à saúde de quem consome esse alimento. Além disso, podem causar prejuízos à indústria de laticínios, pois a adição de substâncias químicas ou remoção de componentes do leite pode prejudicar a fabricação de seus derivados, como, por exemplo, diminuiç̧ão do rendimento industrial (ROSA et al., 2015; ROCHA et al., 2015).

Por ser um alimento extremamente importante na dieta humana e por constituir matériaprima para a indústria de alimentos, as avaliações da composição, qualidade, segurança e integridade do leite cru são extremamente relevantes e devem ser constantemente investigadas e reportadas a fim de alertar às autoridades sobre a importância da apropriada e rigorosa inspeção de produtos de origem animal.

Dessa forma, a verificação da qualidade físicoquímica do leite cru está integrada a esse contexto $\mathrm{e}$ é crucial para se ter conhecimento da realidade, no Brasil, da qualidade da matéria-prima leite recebida e beneficiada nas indústrias de laticínios de diferentes locais do país.

0 objetivo do presente trabalho foi investigar a qualidade do leite cru recebido em um laticínio sob Serviço de Inspeção Federal (SIF) no município de Lima Duarte-MG (zona da mata mineira), mediante análises físico-químicas e verificar a conformidade com a legislação vigente.

\section{METODOLOGIA}

Este estudo consiste em uma pesquisa descritiva, no qual foram analisadas 51 amostras de leite cru em um laticínio sob SIF no município de Lima Duarte, Minas Gerais, no período compreendido entre agosto e outubro de 2018.

Os seguintes testes foram realizados diariamente em todas as amostras de leite cru recebidas pela indústria em questão: determinação da presença de antimicrobianos, teste do álcoolalizarol, pH, acidez titulável, determinação do índice crioscópico, densidade, extrato seco total (EST), extrato seco desengordurado (ESD) e de proteína, lactose, gordura. Além desses testes, foi realizada, em dias aleatórios, pesquisa de reconstituintes de densidade (amido, cloretos e sacarose), conservantes (peróxido de hidrogênio e formol) e neutralizantes de acidez (bicarbonato de sódio e hidróxido de sódio).

\subsection{DETERMINAÇÃO DA PRESENÇA DE ANTIMICROBIANOS}

Para determinar a presença de antimicrobiano no leite, foi utilizado o kit BetaStar ${ }^{\circledR}$ S Combo (Neogen do Brasil), o qual compreende um ensaio rápido, qualitativo, de uma etapa, para a detecção de antibióticos beta-lactâmicos e tetraciclinas em leite cru, misturado ou com valores abaixo dos Limites Máximos de Resíduos (LMR). A análise foi realizada de acordo com as instruções do fabricante (NEOGEN, 2018).

\subsection{TESTE DO ÁLCOOL-ALIZAROL, ACIDEZ TITULÁVEL $\mathrm{EpH}$}

Esse grupo de testes representa análises importantes a fim de se verificar a estabilidade do leite cru ao aquecimento e determinam direta ou indiretamente a acidez do leite.

0 teste do álcool-alizarol compreende um teste rápido, que pode ser realizado nas propriedades rurais e nas indústrias laticinistas e, de acordo com a IN 76/2018 (BRASIL, 2018a), deve ser realizado em uma concentração mínima de $72 \%$ v/v. A interpretação do resultado do teste ocorre de acordo com a coloração obtida após a mistura de amostra de leite e reagente e ainda com a presença ou não de floculação. Em leites estáveis, normais, espera-se como resultado a coloração vermelho-tijolo sem a presença de floculação. Já amostras que apresentem resultados de coloração amarela com presença de coagulação são consideradas ácidas. E, ainda, amostras com resultado final de coloração violeta, sem presença de coagulação, podem indicar suspeita de fraudes de adição de água ou de compostos alcalinos (neutralizantes de acidez) ao leite. 
0 teste de acidez titulável representa um teste de rotina realizado pelo laticínio, sendo de amplo uso na inspeção industrial e sanitária do leite e derivados, bem como na elaboração de derivados lácteos, permitindo avaliar o estado de conservação e eventuais anormalidades no produto. (TRONCO, 2013). Nessa prova, a determinação da acidez consiste na titulação de determinado volume de leite por uma solução alcalina de concentração conhecida (hidróxido de sódio 0,111 (1/9) mol/L), utilizando como indicador a fenolftaleína. 0 resultado é expresso em gramas de ácido lático/100 mL, sendo que o leite cru deve apresentar valores entre 0,14 e 0,18 de ácido lático/100 mL para ser considerado aprovado nesse teste (BRASIL, 2018a).

0 teste do álcool-alizarol e de acidez titulável, no presente trabalho, foram realizados de acordo com Tronco (2013).

$A$ acidez do leite também pode ser observada sob outro aspecto: a acidez atual. A acidez atual corresponde ao pH com valores de 6,4 a 6,9 no leite recém-ordenhado (média 6,6 a 6,8), que se coagula ao alcançar o ponto isoelétrico da caseína $(4,6$ a 4,7) em uma temperatura de $20^{\circ} \mathrm{C} .0 \mathrm{pH}$ pode ser determinado pelo uso de equipamentos (potenciômetros) ou com indicadores de pH: alizarina, amarelo de nitrazina, púrpura de bromocresol (TRONC0, 2013). No presente trabalho, essa análise foi realizada em equipamento pHmetro Modelo pH Classic. 0 eletrodo do pHmetro foi colocado em uma amostra de leite cru para determinação do pH. Após o eletrodo estar em contato com 0 leite foi necessário acionar 0 comando para 0 aparelho fazer a leitura, que foi expressa na tela do mesmo. Na legislação brasileira, não há valores estabelecidos para $0 \mathrm{pH}$ do leite cru, entretanto, espera-se, em um leite cru normal, resultado entre 6,4 e 6,9. Valores inferiores a 6,4 são indicativos de leite ácido, ocasionado, por exemplo, por proliferação microbiana excessiva, e acima de 6,9 de leite alcalino, ocasionado, por sua vez, por fraudes com adição de neutralizantes de acidez, conservantes ou por aguagem do produto.

\subsection{DETERMINAÇÃO DO ÍNDICE CRIOSCÓPICO E DENSIDADE}

0 índice crioscópico ou crioscopia do leite corresponde à medição do ponto de congelamento do produto e deve apresentar resultados entre $-0,530$ e $-0,555^{\circ} \mathrm{H}$ (graus Hortvet), 0 que corresponde a valores entre $-0,512$ e $-0,536^{\circ} \mathrm{C}$ (graus Celsius) (BRASIL, 2018a). A determinação de fraude no leite por aguagem corresponde à aplicação mais usual da crioscopia em laticínios, em razão da diminuição do valor nutricional e na queda do rendimento na fabricação de derivados lácteos, mas também é útil em programas de gerenciamento de qualidade do processamento de leite e derivados (PEREIRA et al., 2001).

No presente trabalho, a crioscopia foi determinada colocando-se $2,5 \mathrm{~mL}$ de leite cru em tubo de ensaio para crioscopia e utilizando-se 0 crioscópio MK 540 flex portátil TR. 0 equipamento expressa o resultado na tela do mesmo.

A determinação da densidade do leite também é uma prova que pode ser realizada na tentativa de detecção de fraudes, tais como a aguagem e desnate. Para a realização dessa prova, utilizou-se 0 termolactodensímetro, de acordo com Tronco (2013), realizando-se a determinação da densidade relativa. Os valores de densidade relativa a $15^{\circ} \mathrm{C}$ esperados para o leite cru são entre 1,028 e 1,034 (BRASIL, 2018a). Resultados abaixo de 1,028 podem sugerir fraude por aguagem e, acima de 1,034, desnate.

\subsection{DETERMINAÇÃO DA QUANTIDADE DE GORDURA, EST E ESD}

Para análise de gordura utilizou-se 0 método de Gerber, de acordo com Pereira et al. (2001). De acordo com a IN 76/2018, o teor mínimo de gordura no leite cru deve ser de $3,0 \mathrm{~g} / 100 \mathrm{~g}$.

A determinação do EST das amostras de leite foi realizada utilizando-se o disco de Ackermann, a partir dos resultados já conhecidos de densidade a $15^{\circ} \mathrm{C}$ e do teor de gordura. 0 teor mínimo de sólidos 
totais no leite cru deve ser de $11,4 \mathrm{~g} / 100 \mathrm{~g}$ (BRASIL, 2018a).

Já o resultado do ESD foi obtido por cálculo da diferença ente EST e gordura, pela fórmula: extrato seco desengordurado = extrato seco total gordura (TRONCO, 2013). 0 teor mínimo de sólidos não gordurosos no leite cru deve ser de $8,4 \mathrm{~g} / 100 \mathrm{~g}$ (BRASIL, 2018a).

\subsection{DETERMINAÇÃO DA QUANTIDADE DE PROTEÍNA E LACTOSE}

Para determinação de proteínas e lactose das amostras de leite cru, utilizou-se 0 analisador de leite Master Classic. As amostras foram colocadas em um recipiente específico e o mesmo foi encaixado na parte frontal do analisador para que as amostras fossem sugadas e analisadas. Os resultados são visualizados no painel digital do analisador e também são impressos em uma impressora que está acoplada no mesmo. 0 resultado esperado para proteína e lactose em leite cru é de 2,9 e 4,3 g/ $100 \mathrm{~g}$, respectivamente (BRASIL, 2018a).

\subsection{PESQUISA DE RECONSTITUINTES DE DENSIDADE, CONSERVANTES E NEUTRALIZANTES DE ACIDEZ}

Para pesquisa de reconstituintes de densidade (amido, cloretos e sacarose), conservantes (peróxido de hidrogênio e formol) e neutralizantes de acidez (bicarbonato de sódio e hidróxido de sódio) foram utilizados testes qualitativos, rápidos, baseados na coloração final da amostra de leite cru.

A legislação brasileira proíbe a adição de quaisquer uma dessas substâncias ao leite cru (BRASIL, 2017) e, portanto, quando detectadas são consideradas adulterações.

Os reconstituintes de densidade geralmente são adicionados ao leite na tentativa de mascarar uma fraude inicial, a aguagem, a qual o produtor de leite muitas vezes a realiza com 0 intuito de aumentar 0 volume de leite, uma vez que o mesmo é remunerado de acordo com o volume de leite produzido. Como a aguagem altera a densidade e a crioscopia do leite, a adição de reconstituintes de densidade pode tentar evitar essa alteração de resultado.

Já os conservantes são adicionados ao leite, quando o produtor suspeita de má qualidade higiênico-sanitária na ordenha ou armazenamento do produto. Dessa forma, por ser excelente meio de cultura, o leite está muito propício à proliferação microbiana e às alterações em decorrência dessa, por exemplo, acidez. Com isso, essas substâncias químicas poderiam retardar o desenvolvimento de micro-organismos no leite.

$E$, por fim, os neutralizantes de acidez são substâncias adicionadas ao leite quando 0 mesmo já apresenta resultado de acidez elevado, em consequência de deterioração microbiana. A adição desses químicos seria uma tentativa de evitar que 0 leite cru seja reprovado nas provas de álcool-alizarol, acidez titulável e pH.

A pesquisa de cada uma dessas substâncias foi realizada de acordo com Pereira et al. (2001).

No presente trabalho, foi realizada análise estatística descritiva dos dados observados, com a distribuição de frequências simples e relativa, bem como a medida de tendência central (média) e de variabilidade (desvio-padrão).

\section{RESULTADOS}

Nas Tabelas 1 e 2 são apresentados os resultados de cada análise realizada nas 51 amostras de leite cru obtidas em um laticínio do município de Lima Duarte - MG. 
Tabela 1. Determinação da acidez titulável, pH, densidade e crioscopia de amostras de leite cru em um laticínio do município de Lima Duarte - MG

\begin{tabular}{|c|c|c|c|c|}
\hline & \multicolumn{4}{|c|}{ Parâmetros analisados } \\
\hline Amostras & $\begin{array}{c}\text { Acidez titulável }(\mathrm{g} / 100 \mathrm{~g}) \\
\text { (Padrão legal: } 0,14 \mathrm{a} 0,18 \mathrm{~g} \text { ácido } \\
\text { lático/mL) }\end{array}$ & $\begin{array}{c}\text { pH } \\
\text { (Padrão legal: não há) }\end{array}$ & $\begin{array}{c}\text { Densidade a } 15^{\circ} \mathrm{C} \\
\text { (Padrão legal: } 1,028 \text { a } \\
1,034)\end{array}$ & $\begin{array}{c}\left.\text { Crioscopia ( }{ }^{\circ} \mathrm{H}\right) \\
\text { (Padrão legal: }-0,530 \\
\text { a -0,555) }\end{array}$ \\
\hline $\mathrm{A} 1$ & 0,17 & 6,9 & 1030 & $-0,546$ \\
\hline $\mathrm{A} 2$ & 0,17 & 6,8 & 1029 & $-0,552$ \\
\hline A3 & 0,16 & 6,4 & 1029 & $-0,552$ \\
\hline A4 & 0,17 & 6,8 & 1028 & $-0,552$ \\
\hline A5 & 0,16 & 6,9 & 1029 & $-0,549$ \\
\hline A6 & 0,17 & 6,9 & 1029 & $-0,551$ \\
\hline A7 & 0,16 & 6,9 & 1028 & $-0,547$ \\
\hline A8 & 0,16 & 6,7 & 1028 & $-0,550$ \\
\hline A9 & 0,16 & 6,9 & 1029 & $-0,550$ \\
\hline A10 & 0,17 & 6,8 & 1029 & $-0,540$ \\
\hline A11 & 0,17 & 6,9 & 1029 & $-0,548$ \\
\hline A12 & 0,16 & 6,6 & 1029 & $-0,549$ \\
\hline A13 & 0,16 & 6,9 & 1028 & $-0,539$ \\
\hline A14 & 0,16 & 6,9 & 1029 & $-0,549$ \\
\hline A15 & 0,16 & 6,7 & 1027 & $-0,541$ \\
\hline A16 & 0,16 & 6,6 & 1028 & $-0,547$ \\
\hline A17 & 0,16 & 6,7 & 1030 & $-0,560$ \\
\hline A18 & 0,16 & 6,9 & 1029 & $-0,547$ \\
\hline A19 & 0,16 & 6,9 & 1028 & $-0,546$ \\
\hline A20 & 0,16 & 6,6 & 1028 & $-0,549$ \\
\hline A21 & 0,17 & 6,8 & 1029 & $-0,550$ \\
\hline A22 & 0,17 & 6,8 & 1028 & $-0,545$ \\
\hline A23 & 0,16 & 6,8 & 1028 & $-0,545$ \\
\hline A24 & 0,16 & 6,8 & 1029 & $-0,542$ \\
\hline A25 & 0,16 & 6,8 & 1029 & $-0,542$ \\
\hline A26 & 0,16 & 6,8 & 1031 & $-0,542$ \\
\hline A27 & 0,16 & 6,8 & 1028 & $-0,543$ \\
\hline A28 & 0,16 & 6,8 & 1029 & $-0,550$ \\
\hline A29 & 0,16 & 6,8 & 1028 & $-0,541$ \\
\hline A30 & 0,16 & 6,8 & 1029 & $-0,549$ \\
\hline A31 & 0,16 & 6,6 & 1029 & $-0,542$ \\
\hline A32 & 0,16 & 6,6 & 1030 & $-0,546$ \\
\hline A33 & 0,16 & 6,7 & 1030 & $-0,550$ \\
\hline A34 & 0,16 & 6,8 & 1027 & $-0,548$ \\
\hline A35 & 0,16 & 6,8 & 1027 & $-0,548$ \\
\hline
\end{tabular}




\begin{tabular}{|c|c|c|c|c|}
\hline A36 & 0,17 & 6,9 & $\mathbf{1 0 2 7}$ & $-0,546$ \\
\hline A37 & 0,16 & 6,9 & $\mathbf{1 0 2 7}$ & $-0,546$ \\
\hline A38 & 0,17 & 6,7 & 1028 & $-0,538$ \\
\hline A39 & 0,16 & 6,8 & 1028 & $-0,538$ \\
\hline A40 & 0,16 & 6,7 & $\mathbf{1 0 2 7}$ & $-0,545$ \\
\hline A41 & 0,17 & 6,8 & $\mathbf{1 0 2 7}$ & $-0,545$ \\
\hline A42 & 0,16 & 6,8 & 1028 & $-0,536$ \\
\hline A43 & 0,17 & 6,8 & 1028 & $-0,546$ \\
\hline A44 & 0,16 & 6,7 & $\mathbf{1 0 2 5}$ & $-0,546$ \\
\hline A45 & 0,16 & 6,8 & $\mathbf{1 0 2 7}$ & $-0,549$ \\
\hline A46 & 0,16 & 6,8 & 1028 & $-0,549$ \\
\hline A47 & 0,16 & 6,8 & 1028 & $-0,548$ \\
\hline A48 & 0,17 & 6,8 & 1028 & $-0,546$ \\
\hline A49 & 0,16 & 6,8 & $\mathbf{1 0 2 7}$ & $-0,551$ \\
\hline A50 & 0,16 & 6,9 & 1028 & $-0,550$ \\
\hline A51 & 0,17 & 6,8 & 1028 & $-0,550$ \\
\hline Média & 0,1627 & 6,8 & 1028 & $-0,546$ \\
\hline Desvio & 0,004 & 0,10 & 1,04 & 0,004 \\
\hline padrão & & & & \\
\hline
\end{tabular}

Amostra com algum dos parâmetros em negrito significa que não está em conformidade com a legislação.

Tabela 2. Determinação da gordura, proteína, lactose, EST e ESD de amostras de leite cru em um laticínio do município de Lima Duarte - MG

\begin{tabular}{|c|c|c|c|c|c|}
\hline \multicolumn{5}{|c|}{ Parâmetros analisados } & \\
\hline Amostras & $\begin{array}{c}\text { Gordura } \\
\mathbf{( g / 1 0 0 )} \\
\text { (Mín. 3,0) }\end{array}$ & $\begin{array}{c}\text { Proteína } \\
\mathbf{( g / 1 0 0 g )} \\
\mathbf{( M i n . ~ 2 , 9 )}\end{array}$ & $\begin{array}{c}\text { Lactose } \\
\mathbf{( g / 1 0 0 g}) \\
\mathbf{( M i ́ n . ~ 4 , 3 ) ~}\end{array}$ & $\begin{array}{c}\text { EST } \\
\mathbf{( g / 1 0 0 g}) \\
\text { (Mín. 1,4) }\end{array}$ & $\begin{array}{c}\text { ESD } \\
\mathbf{( g / 1 0 0 g}) \\
\text { (Mín. 8,4) }\end{array}$ \\
\hline A1 & 3,9 & $\mathbf{2 , 8 1}$ & 4,34 & 12,6 & 8,7 \\
\hline A2 & 3,7 & $\mathbf{2 , 8 5}$ & 4,39 & 12,5 & 8,8 \\
\hline A3 & 3,9 & 2,93 & 4,53 & 13,0 & 9,1 \\
\hline A4 & 4,1 & $\mathbf{2 , 8 0}$ & 4,34 & 12,8 & 8,7 \\
\hline A5 & 3,7 & $\mathbf{2 , 8 2}$ & 4,35 & 12,5 & 8,8 \\
\hline A6 & 3,9 & 2,93 & 4,52 & 13,0 & 9,1 \\
\hline A7 & 4,5 & 2,90 & 4,52 & 13,5 & 9,0 \\
\hline A8 & 3,6 & $\mathbf{2 , 8 1}$ & 4,31 & 12,3 & 8,7 \\
\hline A9 & 3,6 & $\mathbf{2 , 8 9}$ & 4,89 & 12,5 & 8,9 \\
\hline A10 & 3,5 & $\mathbf{2 , 8 3}$ & 4,34 & 12,3 & 8,8 \\
\hline A11 & 4,0 & 2,92 & 4,51 & 13,0 & 9,0 \\
\hline A12 & 3,8 & 2,94 & 4,53 & 13,0 & 9,2 \\
\hline A13 & 3,8 & $\mathbf{2 , 8 6}$ & 4,41 & 12,7 & 8,9 \\
\hline A14 & 4,0 & 2,92 & 4,51 & 13,0 & 9,0 \\
\hline
\end{tabular}




\begin{tabular}{|c|c|c|c|c|c|}
\hline A15 & 4,3 & 2,81 & 4,37 & 13,0 & 8,7 \\
\hline A16 & 3,9 & 2,83 & 4,38 & 12,7 & 8,8 \\
\hline A17 & 4,2 & 3,08 & 4,77 & 13,7 & 9,5 \\
\hline A18 & 3,3 & 2,90 & 4,34 & 12,1 & 8,8 \\
\hline A19 & 3,8 & 2,85 & 4,33 & 12,7 & 8,9 \\
\hline A20 & 3,9 & 2,88 & 4,44 & 12,8 & 8,9 \\
\hline A21 & 3,9 & 2,87 & 4,43 & 12,8 & 8,9 \\
\hline A22 & 4,6 & 2,86 & 4,47 & 13,5 & 8,9 \\
\hline A23 & 3,9 & 2,84 & 4,38 & 12,7 & 8,8 \\
\hline A24 & 4,1 & 2,96 & 4,58 & 13,2 & 9,1 \\
\hline A25 & 4,1 & 2,94 & 4,54 & 13,2 & 9,1 \\
\hline A26 & 3,5 & 3,06 & 4,68 & 12,9 & 9,4 \\
\hline A27 & 3,5 & 2,82 & 4,34 & 13,3 & 9,8 \\
\hline A28 & 4,0 & 2,94 & 5,54 & 13,1 & 9,1 \\
\hline A29 & 3,6 & 2,81 & 4,31 & 12,3 & 8,7 \\
\hline A30 & 4,0 & 2,97 & 4,59 & 13,2 & 9,2 \\
\hline A31 & 3,7 & 2,94 & 4,51 & 12,7 & 9,0 \\
\hline A32 & 3,6 & 2,95 & 4,52 & 12,7 & 9,1 \\
\hline A33 & 3,7 & 2,97 & 4,56 & 12,8 & 9,1 \\
\hline A34 & 4,0 & 2,95 & 4,56 & 11,8 & 7,8 \\
\hline A35 & 3,7 & 2,95 & 4,54 & 11,5 & 7,8 \\
\hline A36 & 4,0 & 2,96 & 4,57 & 11,9 & 7,9 \\
\hline A37 & 3,5 & 2,94 & 4,51 & 11,1 & 7,6 \\
\hline A38 & 3,3 & 2,92 & 4,46 & 11,0 & 7,7 \\
\hline A39 & 3,8 & 2,94 & 4,54 & 11,6 & 7,8 \\
\hline A40 & 3,9 & 2,88 & 4,45 & 11,5 & 7,6 \\
\hline A41 & 4,6 & 2,95 & 4,60 & 12,4 & 7,8 \\
\hline A42 & 3,3 & 2,90 & 4,44 & 11,0 & 7,7 \\
\hline A43 & 3,7 & 2,95 & 4,54 & 11,5 & 7,8 \\
\hline A44 & 4,9 & 2,80 & 4,40 & 11,3 & 6,4 \\
\hline A45 & 4,0 & 2,92 & 4,52 & 11,8 & 7,8 \\
\hline A46 & 3,5 & 2,92 & 4,48 & 11,3 & 7,8 \\
\hline A47 & 3,8 & 2,95 & 4,55 & 11,6 & 7,8 \\
\hline A48 & 3,7 & 2,97 & 4,57 & 11,4 & 7,7 \\
\hline A49 & 3,6 & 2,86 & 4,40 & 11,1 & 7,5 \\
\hline A50 & 3,9 & 2,91 & 4,49 & 11,6 & 7,7 \\
\hline A51 & 3,5 & 2,90 & 4,48 & 12,3 & 8,8 \\
\hline Média & 3,85 & 2,90 & 4,5 & 12,4 & 8,54 \\
\hline Desvio padrão & 0,33 & 0,06 & 0,19 & 0,74 & 0,69 \\
\hline
\end{tabular}

EST $=$ Extrato Seco Total; ESD = Extrato Seco Desengordurado.

Amostra com algum dos parâmetros em negrito significa que não está em conformidade com a legislação. 
Na prova do álcool-alizarol, todas as amostras apresentaram resultado vermelho-tijolo sem floculação, 0 que representa 0 resultado esperado para 0 leite cru estável.

Nas pesquisas de reconstituintes de densidade, conservantes e neutralizantes de acidez, nenhuma amostra mostrou-se positiva para as substâncias analisadas. Assim como foi observado na determinação de antimicrobianos dos grupos dos beta-lactâmicos e tetraciclinas, já que todas as amostras de leite cru analisadas apresentaram resultado negativo nesse teste.

\section{DISCUSSÃO}

Assim como Fernandes e Maricato (2010), que analisaram amostras de leite cru em um laticínio de pequeno porte na zona da mata mineira, todas as amostras analisadas apresentaram valores dentro do padrão determinado pela legislação brasileira (BRASIL, 2018a) em relação à acidez titulável.

Em relação à determinação do $\mathrm{pH}$, todas as amostras apresentaram resultados dentro da faixa de pH esperada para 0 leite cru, 64 a 6,9, corroborando os resultados de Elias et al. (2014) que, durante seu estudo, também não observaram valores de $\mathrm{pH}$ fora dessa faixa. Resultados de $\mathrm{pH}$ do leite fora dos valores esperados podem significar uma alteração na qualidade sanitária e uma instabilidade térmica do produto. Muitas vezes, na rotina das indústrias de laticínios, leites com pH e acidez titulável ligeiramente alterados são destinados à fabricação de derivados lácteos.

Considerando ainda os resultados do teste do álcool-alizarol, observados no presente trabalho, acidez parece não ser um problema no laticínio estudado. Esse é um ponto bastante positivo, uma vez que a acidez do leite causa transtornos no beneficiamento do produto na indústria e está geralmente correlacionada à má qualidade higiênicosanitária desse alimento. Como nenhuma amostra analisada apresentou resultados alterados de acidez, acrescido ao fato de que a pesquisa de antimicrobianos, conservantes e neutralizantes de acidez foram negativas, visto que essas substâncias podem alterar os resultados de acidez, e, ainda, tais amostras serem oriundas de leite cru refrigerado na propriedade rural, é possível sugerir que essas amostras apresentam boa qualidade microbiológica, o que representa um papel crucial em termos de qualidade do leite.

Em reação à densidade, quase $20 \%$ das amostras apresentaram níveis abaixo do estabelecido pela legislação brasileira (BRASIL, 2018a), que é de 1,028 a 1,034, 0 que também foi observado por Venturoso et al. (2007), quando analisaram diversos tipos de leite, encontrando amostras com valores acima e abaixo dos estabelecidos pela legislação, porém diferentemente de Fernandes e Maricato (2010) e Dias et al. (2008), que em seus estudos constataram que todas as amostras se encontravam com densidade entre 1,028 e 1,034.

Valores mais baixos de densidade podem ser indicativos de uma das fraudes mais comum em leite, a aguagem. Apesar de dez amostras apresentarem resultados inferiores ao preconizado pela IN 76/2018, os valores estavam bem próximos da normalidade e, além disso, na determinação do índice crioscópico, que consiste em uma prova de precisão na confirmação da adulteração por adição de água, essas amostras com densidade alterada, bem como todas as demais amostras do presente estudo, apresentaram resultados dentro do intervalo do ponto de congelamento estabelecido pela legislação brasileira que é de $-0,530$ até $-0,555^{\circ} \mathrm{H}, 0$ que não ocorreu no estudo de Mendes et al. (2010), que observaram amostras de leite cru com até $-0,480^{\circ} \mathrm{H}$, sendo esse resultado bem sugestivo de fraude por adição de água.

0 desvio-padrão observado ao se analisar os resultados da determinação do índice crioscópico foi bem baixo, o que demostra ter havido pouca variabilidade nos valores desse teste ao longo do período analisado.

Já para todos os constituintes do leite analisados, foram observadas variações no decorrer do período de análise, o que ocorreu também com Fernandes e Maricato (2010), quando observaram alterações significativas de acordo com o período do ano. Essa variação é esperada, sobretudo, pelo período das análises ter sido relativamente longo e pelo fato de as análises terem sido realizadas no período da 
seca, dessa forma pode ocorrer diminuição no volume do leite produzido pelo animal e, consequentemente, concentração dos nutrientes sólidos

$\mathrm{Na}$ determinação do teor de gordura, assim como Dias (2010), todas as amostras apresentaram mais de $3 \mathrm{~g}$ de gordura por $100 \mathrm{~g}$ de leite, valor mínimo estabelecido pela legislação vigente no Brasil. A média do teor de gordura das amostras foi de 3,85\%, com desvio-padrão de 0,33. Esse valor médio é considerado alto, mas pode ser explicado, como dito anteriormente, pela queda esperada, no período da seca, no volume de leite produzido pelo animal e, então, aumento relativo do teor de gordura.

Em relação ao teor de proteínas, das 51 amostras analisadas, 20 (39\%) apresentaram resultado menor do que $2,9 \mathrm{~g}$ de proteína por $100 \mathrm{~g}$ de leite, valor mínimo exigido pela IN 76/2018. Entretanto, os teores de proteína dessas amostras estão bem próximos do limite mínimo aceitável. Amostras com valores abaixo do estabelecido pela legislação também foram observadas por Fernandes e Maricato (2010) quando analisaram leite cru nos meses de dezembro a fevereiro. Baixa quantidade de proteína pode estar relacionada à degradação proteica ocasionada por proliferação microbiana, entretanto essa não parece ser a causa desse resultado nesse estudo, visto que todas as amostras apresentaram resultado de acidez dentro da normalidade e, no caso de alta contaminação por micro-organismos, é esperada alteração nos testes de acidez, com tendência a acidificação do leite.

A quantidade de proteína no leite cru consiste em um importante parâmetro de qualidade e pode, inclusive, ser utilizada para remuneração do laticínio ao produtor em sistemas de pagamento por qualidade. Considerando o leite cru matéria-prima para a fabricação de derivados lácteos, tais como queijos, leites fermentados e leites desidratados, quanto maior a quantidade desse constituinte no leite tanto maior será 0 rendimento industrial.

$\mathrm{Na}$ determinação do teor de lactose todas as amostras estavam de acordo com a legislação vigente (BRASIL, 2018a), apresentando-se com mais de 4,3\% desse constituinte, o que foi observado também por Perez Junior (2002), que em seu estudo observou uma média de $4,6 \mathrm{~g}$ de lactose em $100 \mathrm{~g}$ de leite. No presente estudo, a quantidade média de lactose nas amostras analisadas foi de $4,5 \mathrm{~g} / 100 \mathrm{~g}$ de leite e 0 desviopadrão de 0,19 . É sabido que a lactose é o componente do leite que menos sofre variação na composição desse alimento, sofrendo menos influência da época do ano, nutrição dos animais, idade, raça, estádio da lactação. Esse fato pode ser observado no presente estudo, visto que o valor do desvio-padrão foi baixo, corroborando a informação de que este nutriente sofre baixa variabilidade.

0 mesmo não foi observado em relação ao extrato seco total (EST), no qual seis amostras (12\%) apresentaram valores inferiores ao mínimo exigido pela legislação vigente no Brasil, $11,4 \mathrm{~g} / 100 \mathrm{~g}$ de leite. Nesse parâmetro físico-químico, o intervalo de variação das amostras foi de 11,0 a 13,7g de EST por $100 \mathrm{~g}$ de leite. Raciocínio análogo ao realizado para as proteínas pode ser feito para o teor de sólidos totais no leite cru. Para a indústria laticinista, sobretudo para aquela que fabrica derivados lácteos, é bem mais interessante economicamente leites com quantidades mais elevadas de EST.

Todavia, problemas maiores foram observados em relação ao extrato seco desengordurado (ESD), pois, das 51 amostras analisadas, 17 (33\%) apresentaram valores abaixo da concentração mínima estabelecida. 0 teor de ESD variou estatisticamente para as diferentes amostras, entre 6,4 e 9,8\%. Uma variação grande e elevado número de amostras com valores anormais de ESD também foram observados por Mendes et al. (2010), porém no estudo dos mesmos a variação foi de 7,92 a 9,63 g/100g de leite. Vale ressaltar que a maioria absoluta das amostras que apresentaram resultado irregular de ESD foram analisadas no final do período da seca e apresentaram alto teor de gordura.

A qualidade da matéria-prima é crucial para a qualidade do alimento processado. Muitos trabalhos científicos, de diferentes regiões do Brasil, (ARAÚJ0 et al., 2016; LIMA et al., 2016; MOTTA et al., 2015; MOURA et al., 2017; TRINDADE et al., 2018) ainda relatam baixa qualidade do leite cru no país, mesmo com a implementação e a atualização de legislações que regulamentam 0 assunto (BRASIL, 2018a; BRASIL, 2018b). No presente estudo, foi observada uma boa qualidade físico-química da matéria-prima leite, 
resultado possivelmente de conscientização e esforços empreendidos por produtores e pela própria indústria.

\section{CONCLUSÃo}

0 laticínio em estudo recebe diariamente leite de diversos produtores e localidades, porém, podese concluir que, mesmo com essa diversidade, a maioria dos parâmetros físico-químico do leite cru recebido por essa indústria se enquadra nos valores estabelecidos pela legislação brasileira e, quando sofreram variações, foram alterações mínimas não comprometendo significativamente a qualidade.

Em suma, a média das amostras recebidas pela indústria enquadra-se nos índices exigidos pela legislação vigente, indicando que o leite produzido na região é de qualidade, conferindo segurança alimentar na matéria-prima.

\section{REFERÊNCIAS}

ARAÚJO, C.A.; MELO, C. S.; FERREIRA, M. N. S.; SANTOS, T. R.; JÚNIOR, J. A. S.; ALBUQUERQUE, A. L. S.; ALMEIDA, D. H. Análise microbiológica do leite cru de vacas comercializado no interior do estado de Alagoas. MV\&Z, São Paulo, v. 14, n. 3, 2016.

ASSIS, J.; FERREIRA, J. D.; MARTINS, H. H.; SCHNEIDER, M. B. Cadeia produtiva do leite no brasil no contexto do comércio internacional. Revista de Ciências Empresariais UNIPAR, Umuarama, v. 17, n. 1 , p. 63-93, 2016.

BRASIL. Ministério da Agricultura, Pecuária e Abastecimento. Instrução Normativa n. 62, de 29 de dezembro de 2011. Diário Oficial [da] República Federativa do Brasil, Brasília, DF, 30 dez. 2011.

BRASIL, Ministério da Agricultura, Pecuária e Abastecimento. Departamento de Inspeção de Produtos de Origem Animal. Regulamento da Inspeção Industrial e Sanitária de Produtos de Origem Animal. Aprovado pelo Decreto n. 30.691 de 29 de março de 1952, alterado pelos Decretos n. 1.225 de 25 de junho de 1962, Decreto n.1236 de 02 de setembro de 1994, Decreto n.1812 de 08 de fevereiro de 1996, Decreto n.2244 de 04 de junho de 1997, Decreto n.9.013 de 29 de março de 2017, Decreto n.9069 de 31 de maio de 2017. Diário Oficial [da] República Federativa do Brasil, Brasília, DF, 01 jun. 2017.

BRASIL. Ministério da Agricultura, Pecuária e Abastecimento. Instrução Normativa n. 76, de 26 de novembro de 2018. Diário Oficial [da] República Federativa do Brasil, Brasília, DF, 30 nov. 2018a.

BRASIL. Ministério da Agricultura, Pecuária e Abastecimento. Instrução Normativa n. 77 , de 26 de novembro de 2018. Diário Oficial [da] República Federativa do Brasil, Brasília, DF, 30 nov. 2018b.

BRUNOZI JÚNIOR, A.C.; ABRANTES, L.A.; FERREIRA, M.A.M.; GOMES, A.P. Mercado e Tributação: Uma abordagem teórica sob a perspectiva de estruturas de mercado na cadeia agroindustrial do leite. Revista Econômica do Nordeste, v.43, n.1, p.93-108, 2012.

CORRÊA, F. T; CAMPOS, S. A. S; PINTO, S. M. Presença de antibióticos, conservantes e reconstituintes em leite UHT e pasteurizado. Demetra: Food, Nutrition \& Health/Alimentação, Nutrição \& Saúde, v. 10, n. 2, p. $289-98,2015$.

DIAS, V. M.; CUNHA, N. P. M.; ALMEIDA JUNIOR, J. F. Determinação de acidez, pH e densidades de leites fluidos comercializados na cidade de São José dos Campos. In: ENCONTRO LATINO AMERICANO DE INICIAÇÃO CIENTÍFICA, 12, 2008, São José dos Campos. Anais eletrônicos [...]. São José dos Campos, Universidade do Vale do Paraíba - UNIVAP, 2008. Disponível em: http://www.inicepg.univap.br/ cd/INIC_2008/anais/arquivosINIC/INIC0339_01_A.pdf. Acesso em: 22 out. 2018.

\section{DIAS, A. M. C. Análises para 0 controlo da qualidade ao leite. 2010. 42f. Monografia} (Especialização Tecnológica em Qualidade Alimentar) - Instituto Politécnico de Coimbra Escola Superior Agrária, Coimbra, 2010.

ELIAS, T.M.; SILVA, A. P. P.; MARTINS JÚNIOR, H. Modelo não linear para relação entre proteína e extrato seco desengordurado do leite. Revista da Estatística da Universidade Federal de Ouro Preto, 
Ouro Preto, v. 3, p. 629-633, 2014.

EMBRAPA. EMPRESA BRASILEIRA DE PESQUISA AGROPECUÁRIA - EMBRAPA. Gado do Leite. Importância Econômica. Juiz de Fora: EMBRAPA Gado de Leite. 2016. Disponível em: https:// sistemasdeproducao.cnptia.embrapa.br/FontesHTML/ Leite/LeiteCerrado/importancia.html. Acesso em: 26 set. 2019.

OECD-FA0. FOOD AND AGRICULTURE ORGANIZATION OF THE UNITED NATIONS. Agricultural outlook 2019-2028. p. 180-189. 2019. Disponível em: http://www.fao.org/agriculture/dairy-gateway/milkproduction/en/\#.V3AZwbgrLIV. Acesso em: 26 set. 2019.

FERNANDES, V. G.; MARICAT0, E. Análises físicoquímicas de amostras de leite cru de um laticínio em Bicas - MG. Revista do Instituto de Laticínios Cândido Tostes, Juiz de Fora, v. 375, p. 3-10, 2010.

KARTHEEK, M.; A.; SMITH, A.; KOTTAI MUTHU, A.; MANAVALAN, R. Determination of adulterants in food: a review. Journal of Chemical and Pharmaceutical Research, v.3, n.2, p. 629-636, 2011.

LIMA, A. S.; LIMA, R. F.; SILVA, E. V.; TARGINO, A. N.; TARGINO, M. V. P. padrões físico-químicos e microbiológicos do leite cru comercializado em município do interior da Paraíba. Revista Verde de Agroecologia e Desenvolvimento Sustentável, João Pessoa, v. 11, n. 3, p. 80-85, 2016.

MENDES, C. G.; SAKAMOTO, S. M.; SILVA, J. B. A.; JÁCOME, C. G. M.; LEITE, A. L. Análises físicoquímicas e pesquisa de fraude no leite informal comercializado no município de Mossoró, RN. Revista Ciência Animal Brasileira, Goiânia, v. 11, n. 2, 2010. Disponível em: https://www.revistas.ufg.br/vet/article/ view/1146/6839. Acesso em: 22 out. 2018.

MOTTA, R.G.; SILVA, A.V.; GIUFFRIDA, R.; SIQUEIRA, A.K.; PAES, A.C.; MOTTA, I.G.; LISTONI, F.J.P.; RIBEIRO, M.G. Indicadores de qualidade e composição de leite informal comercializado na região Sudeste do Estado de São Paulo. Pesquisa Veterinária Brasileira, v. 35, n. 5, p. 417-423, 2015.
MOURA, R.C.; SOUZA, J. S.; FERREIRA, R. C.; RIZZATTI, I. M. Análise físico-química e microbiológica do leite cru comercializado em Roraima. Boletim do Museu Integrado de Roraima, Boa Vista, v. 11, n. 2, p. 2938, 2017.

NEOGEN. Kit BetaStar S Combo: instruções para utilização. Indaiatuba: Neogen, 2018. 2p.

PEREIRA, D. B. C.; SILVA, P. H. F.; COSTA JÚNIOR, L. C. G.; OLIVEIRA, L. L. Físico-química do leite e derivados: métodos analíticos. 2. ed. Juiz de Fora: EPAMIG, 2001. 234p.

PEREZ JUNIOR, F. Porcentagem de gordura, proteína e lactose em amostras de leite de tanques. 2002. 76f. Dissertação (Mestrado em Ciências Veterinárias) - Universidade Federal do Paraná, Curitiba, 2002.

PILA, J. Carta leite: maiores laticínios do Brasil em 2016. Bebedouro: Scot Consultoria, 2017. Disponível em: https://www.scotconsultoria.com. br/noticias/cartas/45663/carta-leite-maioreslatic\%C3\%ADnios-do-brasil-em-2016.htm. Acesso em: 12 nov. 2018.

PINTO, M. S.; CASSOLI, L. D.; MACHADO, P. F.; CARRIJO, K. F.; FRANCO, R. M. Contagem bacteriana total do leite cru no Paraná, São Paulo e Minas Gerais após a implementação da Instrução Normativa N ${ }^{0}$ 51/2002. Pubvet, Londrina, v. 6, n. 12, p. 1-14, 2012.

PROTTA, H. R.; MARICATO, E.; BAPTISTA, E. B.; DIAS, A. M. N. Qualidade físico-química e microbiológica de leite cru clandestino e de leite pasteurizado inspecionado no município de Juiz de Fora - MG. Higiene Alimentar, São Paulo, v. 31, n. 266-267, p. 2241-2245, 2017.

ROCHA, P. C. A.; CUNHA, L. M. M.; MACHADO, A. V.; \& DE OLIVEIRA COSTA, R. Análises microbiológicas do leite e tipos de adulterações. Revista Brasileira de Agrotecnologia, v. 5, n. 1, p, 01-06, 2015.

ROSA, L. S.; GARBIN, C. M.; ZAMBONI, L.; \& BONACINA, M. S. Avaliação da qualidade físicoquímica do leite ultra pasteurizado comercializado no município de Erechim-RS. Vigilância Sanitária em 
Debate: Sociedade, Ciência \& Tecnologia, v. 3, n. 2, p. 99-107, 2015.

SOARES, F. A. C. Composição do leite: fatores que alteram a qualidade química. Porto Alegre: Universidade Federal do Rio Grande do Sul, 2013.

VENTUROSO, R. C., ALMEIDA, K. E. RODRIGUES, A. M.; DAMIN, M. R.; OLIVEIRA, M. N. Determinação da composição físico-química de produtos lácteos: estudo exploratório de comparação de resultados obtidos por metodologia oficial e por ultra-som.

Brazilian Journal of Pharmaceutical Sciences, São Paulo, v. 43, n. 3, p. 607-613, 2007.

TERRA VIVA. Os 20 maiores laticínios captam $25,4 \%$ da produção mundial de leite.

Brasília, 2016. Disponível em: http://www. terraviva.com.br/site/index. php?option=com k2\&view=item\&id=6379:0s-20-maioreslaticinioscaptam-25-4-da-producao-mundial-de-leite $>$. Acesso em: 12 nov. 2018.

TRINDADE, L. C. A.; MARTINS, M. L.; MARTINS, J. M.; MARTINS, A. D. 0. Qualidade de leite cru comercializado informalmente no município de Rio Pomba-MG. Higiene Alimentar, São Paulo, v. 32, n. 284/285, p. 72-76, 2018.

TRONCO, V. M. Manual para inspeção da qualidade do leite. 5. ed. Santa Maria: Ed. da UFSM, 2013.

$208 p$.

ZACARCHENCO, P. B.; VAN DENDER, A. G. F.; REGO, R. A. (ed). Brasil Dairy Trends 2020. Campinas: ITAL, 2017. 343p.

Recebido em: 18/09/2019

Aceito em: 21/10/2019 